\title{
QUANTILE REGRESSION OF GERMAN STANDARD FARMLAND VALUES: DO THE IMPACTS OF DETERMINANTS VARY ACROSS THE CONDITIONAL DISTRIBUTION?
}

\author{
FRIEDERIKE LEHN* \\ University of Hohenheim, Institute of Farm Management, Stuttgart, Baden-Württemberg, Germany \\ ENNO BAHRS \\ University of Hohenheim, Institute of Farm Management, Stuttgart, Baden-Württemberg, Germany
}

\begin{abstract}
Because of considerably increased farmland prices, not only in Germany, the question arises whether farmland is still affordable for farmers. Hence, there is a call for price caps. If farmland prices are to be capped by political intervention, identifying the main farmland price determinants especially for the highest prices is essential. Using quantile regression for German standard farmland values, we find heterogeneous relationships across the estimated quantiles for several covariates. Nonagricultural factors are often more pronounced at the upper tail of the conditional distribution. We recommend focusing primarily on factors in the upper quantiles to prevent further farmland price increases.
\end{abstract}

Keywords. Farmland market intervention, farmland values, quantile regression JEL Classification. Q15

\section{Introduction}

Farmland prices considerably increased during the last decade in many countries around the world (Borchers, Ifft, and Kuethe, 2014; European Union, 2018; U.S. Department of Agriculture, National Agricultural Statistics Service, 2016). In Germany, farmland prices more than doubled from $€ 8,909$ to $€ 22,310 /$ ha on average between 2006 and 2016. Meanwhile, mobility of farmland remained relatively stable at approximately $0.7 \%$ of total agricultural area sold per year. On average, 2.08 hectares was sold per transaction. However, the German agricultural land market is characterized by significant regional differences. Characteristics of the farmland market considerably differ between West and East Germany. In West Germany, less farmland and smaller parcels are sold, but farmland is much more expensive. Price variation becomes obvious at federal

This work was supported by the H. Wilhelm Schaumann Foundation, Hamburg, Germany.

*Corresponding author's e-mail: Friederike_menzel@uni-hohenheim.de 
state level. In 2016, prices ranged from the lower bound of about $€ 10,000 /$ ha in federal states such as Saarland and Thuringia to the upper bound of up to $€ 40,000$ and $€ 50,000 /$ ha in North Rhine-Westphalia (NRW) and Bavaria, respectively (Federal Statistical Office [Destatis], 2017a). Within some federal states, price variation is even higher. Farmland rental rates showed a similar development, even though relative price increases were smaller. Therefore, in combination with a low mobility, the access of land through the rental market is also challenging. Moreover, owing farmland has advantages for farmers such as planning security and flexibility, property rights, and better access to capital.

Some stakeholders of farmland markets have critically noted that the recent farmland price level is already much higher than the earning capacity per hectare for many farmers. To ensure that farmland will still be affordable for farmers, they advocate for political interventions like price caps and sufficient deterrents for farmland market entry by nonagricultural investors (Federal Government Working Group [BLAG], 2015). In a recently published communication, the European Commission recognizes the increasing problems on the farmland market as well as the needs for regulation. Furthermore, the European Commission (2017) confirms that regulations of the farmland market by national law, which currently ranks high on the political agenda of a number of countries, are consistent with European legislation under certain conditions. The communication underlines the current relevance of the topic and the need for further research. This is particularly true for Germany as governments of several federal states are currently working on stricter regulations for the farmland market, which also include the objective to prevent or at least to limit further price increases. Hence, there should be considerable political interest in factors influencing farmland prices to create the best possible regulations.

Because of a vast body of related literature, Hüttel et al. (2013) argued that the main farmland price determinants have already been recognized. However, these studies mainly applied regression methods that estimate conditional means of farmland prices given the explanatory variables. This means significant price determinants, which have already been found, initially apply only to the mean farmland price. However, as the proposed stronger interventions include price caps for agricultural land, the interest of our study primarily lies in the most important price drivers of the more expensive farmland rather than only of average farmland prices. Hence, from an agricultural policy perspective, we are especially concerned with the upper tail of the conditional farmland price distribution, and in particular with the significant price-increasing covariates in this specific segment of the conditional distribution.

We analyze the municipal-level standard farmland values (SFVs) for arable land of the German federal state NRW. It provides a favorable study area to empirically analyze various factors influencing farmland values as 
it is characterized by considerably heterogeneous manifestations of potential agricultural and nonagricultural explanatory variables (e.g., soil quality, livestock production, and urban sprawl). However, this also means that the locational conditions for agriculture vary significantly across regions. The implication of this is that the impacts of the explanatory variables may vary along the conditional distribution of farmland values (Nilsson and Johansson, 2013) leading to the problem that the resulting estimates of various effects on the conditional mean may not necessarily be indicative of the size and nature of these effects on the upper tail of the conditional farmland price distribution (März et al., 2016). Moreover, different coefficient estimates at different conditional quantiles would be a manifestation that a pure location shift model (like ordinary least squares [OLS] regression) is inadequate, and a model also allowing scale shifts is needed to explain the relationship between farmland prices and their influencing factors (Mishra and Moss, 2013). For example, an explanatory variable could only be significant in the upper tail, but not in the rest of the conditional distribution. This could result in an insignificant effect when estimating the conditional mean (e.g., by conventional least squares regression). Hence, if only the significant explanatory variables on the conditional mean are considered when developing stricter regulations to limit farmland price increases, the measurement could be ineffective and inefficient or, in the worst case (if the direction of the effect is adversely in the upper quantiles), will lead to counteracting incentives.

Conditional quantile regression enables us to analyze particular segments of the conditional distribution of farmland values. Hence, by estimating a set of conditional quantile functions we are able to uncover potential heterogeneities of the estimated covariate effects across the conditional distribution of farmland values (Koenker, 2005). ${ }^{1}$ Conditional (on the model covariates) means we want to examine if a specific farmland attribute has a different impact on higherpriced parcels relative to lower-priced parcels that are otherwise similar in all characteristics.

An alternative approach would be an unconditional quantile regression as proposed by Firpo, Fortin, and Lemieux (2009). According to the authors, unconditional quantile regression allows researchers to measure the effect of a small change in the covariate $X$ on the quantiles of the unconditional distribution of the dependent variable $Y$. Looking at the impact of a particular covariate on farmland values, say soil quality, illustrates well the difference between conditional and unconditional quantile regressions. Following Firpo, Fortin, and Lemieux (2009), finding that the positive effect of soil quality estimated using unconditional quantile regressions is smaller at the 90th than at the 10th quantile means that an increasing soil quality reduces the overall farmland

1 In general, the quantile regression has several advantages over conventional least square methods, which are comprehensively explained by Uematsu, Khanal, and Mishra (2013). 
price dispersion as measured by the difference between the 90th and the 10th quantiles of the unconditional farmland price distribution. However, we are not interested in the effect of soil quality on the overall price dispersion, but in the effect on the within-group price dispersion, where the "group" consists of land parcels that share the same values of all the covariates other than soil quality (conditional effect). To answer this question, we have to turn to conditional quantile regression. Here, finding that the positive effect of soil quality is smaller at the 90th than at the 10th quantile means that an increasing soil quality reduces within-group dispersion. Consequently, finding covariates with higher effects at the upper quantiles using conditional quantile regressions means that these covariates increase within-group dispersion, and hence, this would be an indication that stronger interventions with the objective to limit further farmland price increases should particularly take these covariates into account.

Previous studies indicate that it is reasonable to assume that farmland prices are influenced by different determinants in the upper and lower tail of the conditional distribution compared to mean prices (Kostov, 2009b; Mishra and Moss, 2013; Nilsson and Johansson, 2013). With regard to this parameter heterogeneity, Uematsu, Khanal, and Mishra (2013) hypothesized that the attributes of farmland can be divided into "luxury" and "necessity." The luxury attributes may only have an impact at the relatively higher price range, whereas the necessary attributes may only affect prices at the lower price range. Their results showed that residential natural amenities (climate conditions, topography, and proximity to water area), which are rather luxury than necessity attributes, positively affected farmland values, but the impact was often more pronounced at the higher price range.

Despite its advantages, conditional quantile regression is still not commonly used to analyze the German farmland market. Thus, the current combination of proposed price caps and the lack of conditional quantile regression analyses of German farmland values reveals a knowledge gap. Our study tries to fill this gap by analyzing German SFVs for arable land by means of conditional quantile regression.

\section{Related Literature Showing the Benefits of Quantile Regression}

Quantile regression models are increasingly applied in studies dealing with house prices. These studies found substantial variations of the impacts of housing characteristics across the quantiles. These factors included square footage and number of bathrooms (Zietz, Zietz, and Sirmans, 2008), school proximity and scenic view (Kim et al., 2015), proximity to environmental externalities such as animal agricultural facilities (Kuethe and Keeney, 2012), spatial dependence (Liao and Wang, 2012), location within a floodplain (Zhang, 2016), and areas with land subsidence and earth fissures (Yoo and Frederick, 2017). 
Despite its growing application in the real estate sector, quantile regression is less frequently used in agricultural economics literature (Uematsu, Khanal, and Mishraet, 2013). Kostov (2009b) used a spatial quantile regression for analyzing agricultural land sales in Northern Ireland. He found two relatively separate segments of the farmland market. The larger one conformed to the conventional hedonic model with no spatial lag dependence. In contrast, considerable spatial lag dependence was observed at the higher quantiles of the dependent variable, which suggested the hedonic model broke down here. The author also showed that a significantly positive impact of a potential building site within the land parcel was only pronounced at the very high quantiles (i.e., in the more expensive parcels of land). He traced this back to the fact that nonagricultural opportunities would, in general, be more profitable than purely agricultural use of this land. In contrast, no significant effects of the land-quality variables were found at the higher quantiles. Nilsson and Johansson (2013) included the number of seasonal homes as a proxy for rural amenities and the accessibility to population for analyzing Swedish agricultural land prices and showed that these nonagricultural factors seemed to be more important in regions that have conditionally high prices, whereas income support to farmers seemed to be most influential in regions with conditionally low prices. Mishra and Moss (2013) analyzed the effects of off-farm income, farm subsidies, and location of farms on farmland values in the United States using a quantile regression approach. Most effects of the land attributes varied considerably across the quantiles, both in terms of magnitude and direction. Off-farm income, direct farm payments, and a farm's location in a metropolitan county had a positive and significant effect on farmland values, and the magnitude of the coefficients increased monotonically across quantiles. McMillen (2015) used a conditionally parametric version of a quantile regression and showed significant quantile effects with particularly high land values near the urban center and along the transport network in the United States. März et al. (2016) used a Bayesian geoadditive quantile regression to analyze German farmland rental rates and found some noticeable instances of heterogeneity across quantiles, particularly for the estimated effects of livestock density, share of rented agricultural land, and share of rented arable land. In a recent study, Peeters, Schreurs, and van Passel (2017) analyzed the impact of soil contamination on Belgian farmland prices using an unconditional quantile regression and found a significant negative impact of cadmium pollution, but only in the middle range of the distribution. They argued that the heterogeneous impact of soil pollution can be directly related to the variety of amenities that farmland provides (e.g., agricultural production, open space/recreation, and rural living).

All these studies clearly demonstrate that a quantile regression approach provides richer information of the relationship between farmland prices and farmland characteristics that otherwise would have been left unnoticed by using conventional least squares regression. 


\section{Implicit Price Variation of Farmland Characteristics}

Our conceptual framework is the hedonic pricing model. For the discussion of the theoretical foundation, we closely follow Palmquist (1991) and Ready and Abdalla (2005).

According to Rosen's (1974) hedonic pricing model, the price of a heterogeneous good like farmland is determined by a unique set of attribute levels, $x=\left(x_{1}, x_{2}, \ldots, x_{n}\right)$. In particular, $x$ is a vector of agricultural and nonagricultural attributes related to farmland. Hence, the price for which the parcel of land sells is a function of its characteristics:

$$
P=P(x) .
$$

The hedonic pricing function, $P(x)$, describes the equilibrium set of farmland prices, given the population of buyers and the available supply of farmland in a competitive market. ${ }^{2}$ The determination of the hedonic price schedule in the market can be explained by considering the behavior of prospective buyers of farmland. Prospective buyers differ according to a vector of socioeconomic characteristics, $\alpha$. A typical buyer maximizes the utility $U\left(z, x_{1}, \ldots, x_{n} ; \alpha\right)$ from the consumption of the farmland attributes $x$ and a composite good $z$. Thereby, $U$ is subject to the budget constraint $y=z+P\left(x_{1}, \ldots, x_{n}\right)$, where $y$ represents the buyer's income. The first-order conditions for this optimization problem require that the marginal implicit price for each single farmland attribute $x_{n}$, equals the marginal rate of substitution between attribute $x_{n}$ and the composite $\operatorname{good} z$ :

$$
\frac{6 P}{6 x_{n}}=\frac{6 U / 6 x_{n}}{6 U / 6 z}
$$

For marginal changes in $x_{n}$, then, the marginal implicit price of $x_{n}$ measures the buyer's marginal willingness to pay for additional $x_{n}$.

For a parcel of land, the hedonic pricing function in equation (1) can be written as a stochastic equation:

$$
P_{i}=\beta_{0}+\beta_{1} x_{1 i}+\beta_{n} x_{n i}+\varepsilon_{i}, \text { for } I=1, \ldots, I,
$$

where $P_{i}$ is the per hectare price for parcel $i, x$ is the vector of the $n$ characteristics of farmland, $\beta$ is the vector of marginal implicit prices to be estimated, and $e_{i}$ is an error term.

The traditional hedonic approach in equation (3) assumes that the structure is stable across the geographic area and thus that the geographic area can be treated as a single market (Huang et al., 2006; Patton and McErlean, 2003). Under this assumption, conventional least squares regression can be used to

2 For farmland, characteristics are not produced, but their quantity is exogenous to the seller. Hence, the equilibrium price is determined completely by demand once the level of characteristics is given (Palmquist, 1991). 
estimate equation (3) for identifying the implicit prices. However, violation of this assumption can cause misleading results because equilibrium prices may differ from market to market for the same set of attribute levels (Huang et al., 2006). Indeed, with regard to the empirical literature cited previously, concerns exist whether the assumption of a single market holds.

For the sake of argument, we assume that there are two prospective buyers of farmland: On the one hand, there is a farmer who needs the farmland for agricultural production. Thus, his willingness to pay is mainly oriented on or constrained by the agricultural value of farmland. The agricultural value is determined by factors affecting the profitability of agriculture. On the other hand, there is a nonagricultural investor who does not face comparable constraints and his objectives for buying farmland differ (e.g., he may need the farmland for investment diversification, reduction of inflation risks, or speculative purposes). Further, we take into account that farmland prices can be broken down into expected returns from land in its current agricultural use and expected returns from its potential use. As soon as the potential of land conversion to a more profitable nonagricultural land use is only expected by the nonagricultural investor, two segmented markets can be developed (one farmland market for purely agricultural purposes and one farmland market for nonagricultural use of land). Segmentation may not only imply that the farmer and the investor buy farmland of different values, but they may also have group-specific likes and dislikes of certain farmland characteristics (Zietz, Zietz, and Sirmans, 2008). This can be a result of different socioeconomic characteristics $\alpha$ and related differences in preferences. For example, soil quality and proximity to the farm are of prior interest for the farmer because soil quality directly affects the earning capacity of the parcel and the proximity between the parcel and the farm indirectly affects the earning capacity through lower transportation costs. The nonagricultural investor is not interested in the proximity of land to his business place because he does not manage the parcel on his own and may only have limited knowledge of how to assess the soil quality. Consequently, the marginal rate of substitution between a farmland attribute $x_{n}$ and the composite good $z$ in equation (2) may differ for the farmer and the investor. This results in two different implicit prices for the farmland attribute $x_{n}$. For $r$ different groups of buyers, the hedonic pricing model in equation (3) becomes

$$
\begin{aligned}
P_{r i}= & \beta_{r 0}+\beta_{r 1} x_{r i 1}+\beta_{r n} x_{r i n}+\varepsilon_{r i}, \text { for } i=1, \ldots, I \text { and } \\
& r=1, \ldots, R \text { market segments. }
\end{aligned}
$$

In equation (4), the marginal contribution of the different characteristics to the value of farmland is allowed to vary according to the market segment $r$ (Patton and McErlean, 2003). However, segmenting the dependent variable into subsets can create biased parameter estimates (Heckman, 1979). For farmland, the determination of market segments is particularly challenging because of the 


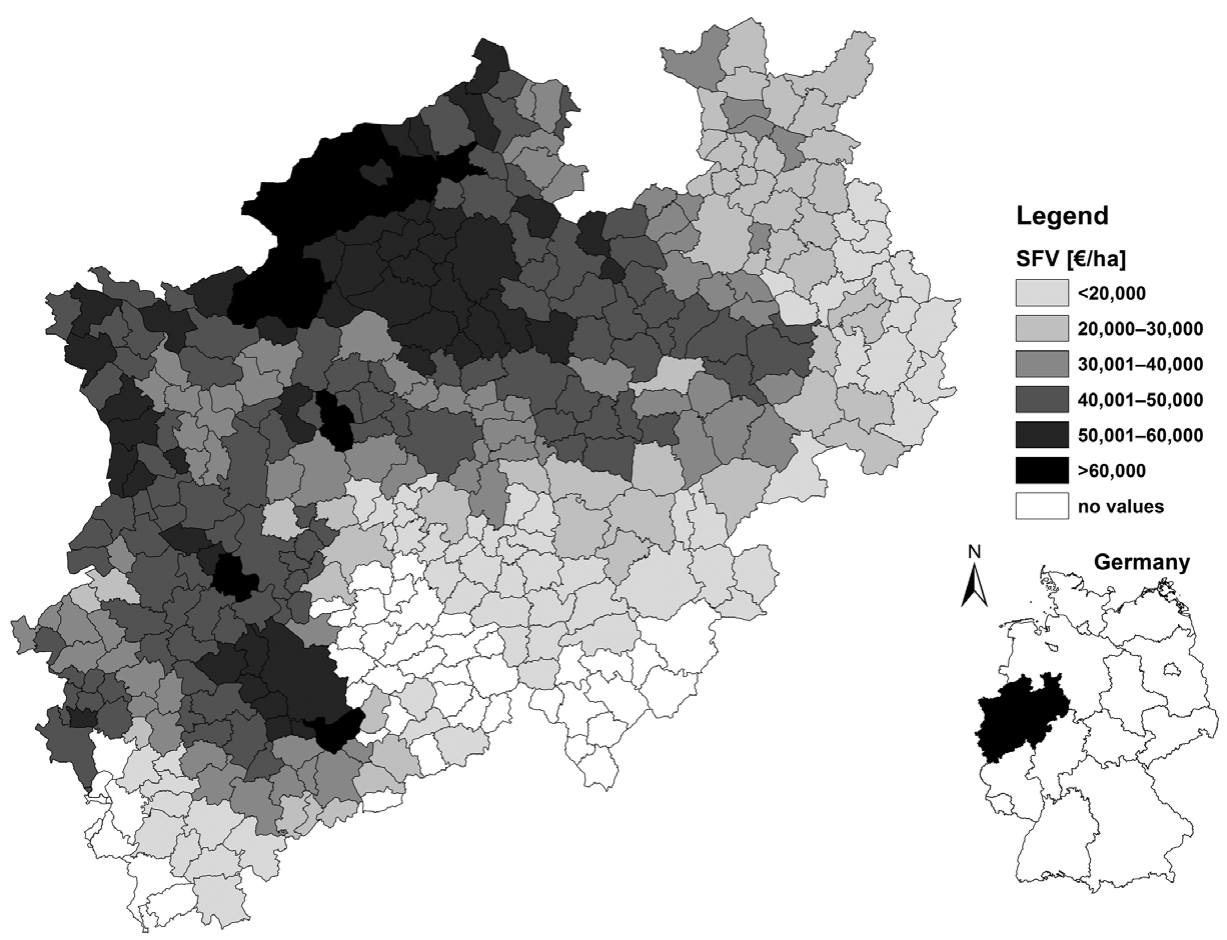

Figure 1. Standard Farmland Values (SFV) for Arable Land at the Municipal Level in North Rhine-Westphalia in 2013 (source: illustration based on GeoBasisDE/BKG, 2015b)

heterogeneity of parcels, buyers, and sellers. In principle, it is reasonable to assume that the preference structure differs among all of the prospective buyers, or, put another way, we can assume that each individual puts a different value on a farmland attribute depending on the characteristics of each individual (e.g., farmer, investor), the individual perception of the farmland attributes (Mishra and Moss, 2013; Uematsu, Khanal, and Mishra, 2013), and subjective future expectations (März et al., 2016).

As stated previously, quantile regression is an appropriate approach to reveal such differences in the preference structure as it allows the implicit prices to vary across the conditional distribution of farmland prices. Moreover, because quantile regression employs the full data set, a market segment selection problem does not arise in the first place (Kim et al., 2015).

\section{Data}

Our study area is the federal state NRW located in northwestern Germany (see Figure 1). The dependent variable is the SFV for arable land as a small-scale 
indicator for farmland prices. Based on legal regulations, regional appraisers determine the SFV annually and report their findings for a defined zone consisting of broadly similar parcels according to the farmland characteristics. The SFV is an average value of nearly all farmland sales obtained from the data on purchasing prices of the real estate appraiser board in NRW. Only arm's length transactions are considered. Unfortunately, the entire data on purchasing prices are not available to the public in general and for science institutions in particular. Thus, the SFV is usually the best available variable for research purposes in Germany. For this analysis, data for the years 2010 to 2013 are available. Figure 1 illustrates the spatial distribution of the SFV for arable land in 2013 at the municipal level for the study area. The mean SFV for arable land is $€ 37,640$ per hectare, ranging from $€ 9,100$ to $€ 76,000$ per hectare. Despite a cluster of the highest SFV in the northwest, there is a gradient from high values in the north and west to low values in the southern and eastern peripheral areas. With this variation of SFV, NRW is an excellent representative of Germany's farmland markets.

Descriptive statistics for the SFV and the covariates used in the hedonic pricing model are given exemplarily for 2013 in Table 1. Land use characteristics are available from the Federal Statistical Office NRW (Landesdatenbank NRW, 2017), and the soil quality index is obtained from the Geological Service of NRW. The average slope of agricultural land was generated based on altitudes given by the digital terrain model of the German Federal Agency for Cartography and Geodesy (BKG) (GeoBasis-DE/BKG, 2015a) and the land use map of the German Federal Institute for Geosciences and Natural Resources (BGR, 2015). The share of two different protected areas (NSG, WSG) was calculated by intersecting the respective map from the State Office for Nature, Environment and Consumer Protection NRW (LANUV, 2015) with the map of administrative regions from the BKG (GeoBasis-DE/BKG, 2015b). Payments for agroenvironmental measures (AUM) were obtained from the published information on recipients of European Union direct payments for the year 2013 (Federal Office for Agriculture and Food [BLE], 2015). Data on biogas and wind power plants in NRW are published by the transmission system operators Amprion and Tennet TSO. The location of the respective plant operator was used as an approximation for the site of the plant. Data on livestock production, number of farms, and the share of full-time farms were obtained from the agricultural census in 2010 (Landwirtschaftszählung, 2010). Factors relating to urban influence were obtained from the database of the Federal Statistical Office NRW (Landesdatenbank NRW, 2017) and the Regional Database Germany (Destatis, 2017b). Distances to cities with at least 100,000 inhabitants (criterion for large cities) were calculated via OpenStreetMap. The distance was measured between the centroids of the municipality and the city. The fastest road distances to all of the large cities were calculated for each municipality, and in each case the shortest distance was selected. 
Table 1. Descriptive Statistics for the Municipal Level Variables for North Rhine-Westphalia in 2013

\begin{tabular}{|c|c|c|c|c|}
\hline Variable & Definition & $\begin{array}{l}\text { Mean (standard } \\
\text { deviation) }\end{array}$ & Minimum & Maximum \\
\hline SFV $[€ / h a]$ & $\begin{array}{l}\text { Standard farmland value for arable } \\
\text { land }\end{array}$ & $37,640(14,994)$ & 9,100 & 76,000 \\
\hline Soil quality $[0 ; 100]$ & $\begin{array}{l}\text { Average soil quality index for arable } \\
\text { land }\end{array}$ & $50.38(15.31)$ & 23.00 & 90.00 \\
\hline $\begin{array}{l}\text { Share of arable land } \\
{[\%]}\end{array}$ & $\begin{array}{l}\text { Share of arable land on total utilized } \\
\text { agricultural area }\end{array}$ & $72.69(18.16)$ & 7.40 & 98.72 \\
\hline Share of UAA [\%] & $\begin{array}{l}\text { Share of utilized agricultural area to } \\
\text { total area }\end{array}$ & $51.06(18.00)$ & 8.57 & 84.43 \\
\hline $\begin{array}{l}\text { Change of UAA } \\
{\left[[\%]^{\mathrm{a}}\right.}\end{array}$ & $\begin{array}{l}\text { Relative change in utilized } \\
\text { agricultural area in comparison to } \\
\text { the year } 2000\end{array}$ & $-3.10(18.17)$ & -48.20 & 275.20 \\
\hline Slope $[\%]$ & $\begin{array}{l}\text { Average slope of utilized agricultural } \\
\text { area }\end{array}$ & $3.03(3.00)$ & 0.18 & 14.84 \\
\hline AUM [€/ha] & $\begin{array}{l}\text { Payments for agroenvironmental } \\
\text { measures per hectare utilized } \\
\text { agricultural area in } 2013\end{array}$ & $22.70(25.12)$ & 0.00 & 299.80 \\
\hline NSG [\%] & Share of nature reserve to total area & $7.07(7.03)$ & 0.00 & 41.87 \\
\hline WSG $2[\%]$ & $\begin{array}{l}\text { Share of water protection area (zone } \\
\text { 2) to total area }\end{array}$ & $1.87(4.72)$ & 0.00 & 46.54 \\
\hline Farms [number] & Number of farms in 2010 & $95.04(65.12)$ & 7 & 355 \\
\hline Farm size $[$ ha/farm] & $\begin{array}{l}\text { Farm size expressed in hectares UAA } \\
\text { per farm }\end{array}$ & $49.72(15.23)$ & 16.58 & 125.10 \\
\hline Full-time share [\%] & Share of full-time farms to all farms & $57.80(14.43)$ & 25.00 & 90.91 \\
\hline $\begin{array}{l}\text { Livestock density } \\
\text { [LSU/ha] }\end{array}$ & $\begin{array}{l}\text { Livestock units (LSU) per hectare } \\
\text { UAA in } 2010\end{array}$ & $0.97(0.61)$ & 0.01 & 3.66 \\
\hline Biogas [kWel./ha] & $\begin{array}{l}\text { Installed electric power of biogas } \\
\text { plants per hectare utilized } \\
\text { agricultural area }\end{array}$ & $0.14(0.21)$ & 0.00 & 1.76 \\
\hline Wind [kWel./ha] & $\begin{array}{l}\text { Installed electric power of wind } \\
\text { turbines per hectare utilized } \\
\text { agricultural area }\end{array}$ & $1.88(2.52)$ & 0.00 & 17.85 \\
\hline $\begin{array}{l}\text { Population density } \\
\quad\left[\text { inhabitants } / \mathrm{km}^{2}\right]\end{array}$ & Population density & $511.70(546.5)$ & 54.98 & 3003 \\
\hline $\begin{array}{l}\text { Population change } \\
{[\%]}\end{array}$ & $\begin{array}{l}\text { Percent change in population to } \\
2000\end{array}$ & $-2.75(5.21)$ & -20.80 & 12.84 \\
\hline $\begin{array}{l}\text { House construction } \\
\text { [number] }\end{array}$ & $\begin{array}{l}\text { Number of residential house } \\
\text { construction permits }\end{array}$ & $62.41(87.20)$ & 2 & 961 \\
\hline $\begin{array}{l}\text { Income } \\
{[€ / \text { inhabitant }]}\end{array}$ & $\begin{array}{l}\text { Average income per inhabitant in } \\
2010\end{array}$ & $15,330(2,944)$ & 10,000 & 49,240 \\
\hline Distance $[\mathrm{km}]$ & Distance to the nearest large city & $30.80(18.79)$ & 0.00 & 95.36 \\
\hline
\end{tabular}

${ }^{a}$ The high maximum value stems from a land use change (fallow to grassland) in the small municipality of Augustdorf (size: 10 hectares) in the year 2009. There are five similar small municipalities, where higher increases of utilized agricultural area $(+15 \%$ to $+89 \%)$ were observed because of land use changes. However, only $5 \%$ of all analyzed municipalities had an increase in the amount of land. This is demonstrated by the negative mean value of this variable.

Source: Calculations based on aforementioned sources. 


\section{Method}

According to our conceptual framework, the implicit prices of farmland characteristics are expected to vary across the conditional distribution of farmland prices. The quantile regression, first proposed by Koenker and Bassett (1978), enables us to statistically examine the extent of this variation across the conditional distribution of SFVs. Unlike OLS regression, quantile regression minimizes the sum of weighted absolute deviations to estimate parameter coefficients for any quantile in the range $0<\tau<1$ conditional on the explanatory variables as

$$
\hat{\beta}(\tau)=\min _{\beta \in R^{K}}\left[\sum_{i \in\left\{i: y_{i} \geq x_{i} \beta\right\}} \tau\left|y_{i}-x_{i} \beta\right|+\sum_{i \in\left\{i: y_{i}<x_{i} \beta\right\}}(1-\tau)\left|y_{i}-x_{i} \beta\right|\right] .
$$

Symmetric weights of the absolute residuals yield the median $(\tau=0.5)$, whereas minimizing the sum of asymmetrically weighted absolute residuals with different weights being placed on positive and negative values yields other quantiles (e.g., $\tau=0.1$ or 0.9) (Koenker and Hallock, 2001). The objective function (equation 5) is not differentiable, but the minimization problem can be solved by linear programming using the simplex method (Koenker, 2005; Uematsu, Khanal, and Mishra, 2013).

The conditional quantile function for $y$ given a set of explanatory variables $X$ can be written as

$$
Q_{\tau}(y \mid X)=X \beta(\tau \mid X)+u \quad \text { for any quantile } \tau \in(0,1),
$$

where $y$ is an $n x 1$ vector of the SFV for arable land in euros per hectare $(n=$ number of observations), $Q_{\tau}(y \mid X)$ is the $\tau$ th quantile of $y$ conditional on the $n x k$ covariance matrix $X$ that includes agricultural and nonagricultural as well as time dummy variables ( $k=$ number of explanatory variables), $\beta(\tau \mid X)$ is a $\tau$ dependent associated $k x 1$ vector of regression coefficients, and $u$ represents the residuals.

However, the quantile regression model in equation (6) does not account for spatial effects (spatial dependence and spatial heterogeneity) that may be present in the data (Anselin, 1988). Different motivations exist to include spatial effects, which are elaborately described in LeSage and Pace (2009). One of their motivations is model uncertainty, which usually applies to hedonic pricing models. According to Kostov (2009a, 2009b), trade-offs arise between spatial dependence and choice of functional form in (agricultural land) price models in the sense that incorrect functional form assumptions can induce spurious spatial dependence or at least "increase" spatial dependence. Nonparametric approaches admit at the start that the true model structure is unknown (McMillen, 2012) and, hence, would avoid the problem of spurious spatial dependence. However, relatively small data sets used in empirical modeling or the complexity of these models (e.g., large numbers of covariates) make nonparametric estimation 
approaches often unfeasible. A spatial quantile regression is a semiparametric estimation method, which at least allows us to alleviate the potential problem of spurious spatial dependence (Kostov, 2009b). ${ }^{3}$

For the farmland sale market, several studies have already identified the existence of spatial effects. Hence, in recent years spatial process models have been favored for analyses of farmland price determinants, and substantial improvements of model fit are shown (Dillard et al., 2013; Feichtinger and Salhofer, 2016; Huang et al., 2006; Hüttel et al., 2013). For a spatially fixed asset like farmland, there are several reasons why spatial dependence can exist. ${ }^{4}$ Spatial dependence can occur in the dependent variable because of spillover effects. In the case of farmland, prices in one municipality can be influenced by realized prices in neighboring areas. This effect arises because buyers typically act as competitors for land within a defined radius around their farms (Breustedt and Habermann, 2011; Hennig and Latacz-Lohmann, 2017). Another reason is that prospective buyers refer to reference prices of comparable and nearby lots on which to base their bids (Hüttel and Wildermann, 2015; Maddison, 2009). To account for such spatial spillovers and to obtain unbiased regression coefficients, a spatial lag model should be applied by using the average neighboring price as an additional explanatory variable (Anselin, 1988). However, to be able to use a price of a comparable lot as a reference, the reference price must be observable before the respective price formation starts (Hüttel and Wildermann, 2015). Hence, we define a row-standardized queen-contiguity spatial weight matrix for generating the spatial lag variable such that the SFV of arable land for a municipality is only determined by the SFVs of adjacent municipalities (according to the queen criterion), which are observed before the respective SFV is determined. As a result, we include a spatiotemporally lagged SFV and treat it as an exogenous explanatory variable. Analyzing the years from 2010 to 2013, for example, the SFV for a municipality in 2013 can only be influenced by SFVs of adjacent municipalities of the years 2010 to 2012. Consequently, the results are only based on the years 2011 to 2013, because we cannot calculate a spatiotemporally lagged SFV for the year 2010. We further account for the time dimension by means of two time dummy variables representing the years 2012 and 2013, respectively. The Moran's I test confirms the existence of spatial autocorrelation in the data (Moran's $I=0.689, P<0.0000$ ), and the robust version of the

3 In addition, problems arising from potential functional misspecification could in general be alleviated as linear quantile regression can usually be considered as an approximation to a more general nonlinear model (Kostov, 2009b).

4 Spatial heterogeneity, which refers to variation in relationships over space (LeSage, 1998), may also be present in the data. For example, if at least one spatially distributed explanatory variable (e.g., climate factors) is omitted, the spatial structure remains in the error term. Quantile regression is able to take unobserved heterogeneity into account and allows for heteroscedasticity among disturbances (Koenker, 2005). The latter can essentially include any forms of spatial error dependence (Kostov, 2009b). Hence, we only consider spatial dependence in the dependent variable. 
Lagrange multiplier (LM) test indicates that spatial dependence in the dependent variable has to be considered (robust LM for spatial lag $=144.91, P<0.0000$ ).

Accordingly, our hedonic pricing model using a quantile regression framework is given by

$$
Q_{\tau}(y \mid X)=\rho_{\text {lag }}(\tau \mid X) W y+X \beta(\tau \mid X)+u,
$$

where $W$ is an $n x n$ spatial weight matrix that defines the relevant neighborhood of each observation by simultaneously considering the time constraints and $\rho_{\text {lag }}$ is the respective coefficient for the exogenously treated spatiotemporally lagged SFV. Now both the regression coefficient $\beta(\tau)$ and the estimation parameter $\rho_{\text {lag }}(\tau)$ are $\tau$-dependent. Because the spatiotemporally lagged variable is treated as an exogenous variable, the conventional quantile regression estimator of Koenker and Bassett (1978) will be consistent. We used the modified version of the Barrodale and Roberts (1980) algorithm to estimate the conditional quantile regression model, which is described in detail in Koenker and d'Orey $(1987,1994)$. The standard errors of the coefficient estimates are computed using bootstrapping ( $x y$-pair method, 200 bootstrap replications).

\section{Results}

The analysis of the estimation results of the spatiotemporal quantile regression model is twofold. On the one hand, we use a graphical representation for the results to give a complete picture of the covariate effects across the conditional distribution of the SFVs for arable land in NRW. We estimate the quantile process from 0.1 to 0.9 in increments of 0.01. Figures 2 and 3 show the estimated coefficients of the quantile regression process together with their $95 \%$ confidence intervals. For comparison, the estimated coefficients and confidence intervals of OLS regression are also plotted. We do not show and describe the plots for the intercept and the insignificant variables. On the other hand, Table 2 shows the estimation results for OLS regression and a subset of selected quantiles to give an overview of the numerical implications of factors influencing SFVs and to compare the coefficients of both methods.

Figure 2 shows the estimation results for the covariates of agricultural characteristics. The share of arable land reveals some differences between both methods. The OLS regression shows the expected significant positive impact because of its indication of good agricultural production conditions and higher returns associated with cropland (Hüttel et al., 2013). An increase of 10\% in the share of arable land causes the SFVs for arable land to increase by $€ 660$ per hectare. In the quantile regression estimation, the effect varies across the quantiles. In the lower half of the conditional distribution, the positive impact is comparable to or partly higher than the OLS regression (€650-€780 per hectare premium for a $10 \%$ increase in the share of arable land), but then the effect steadily decreases until it becomes insignificant in the highest 

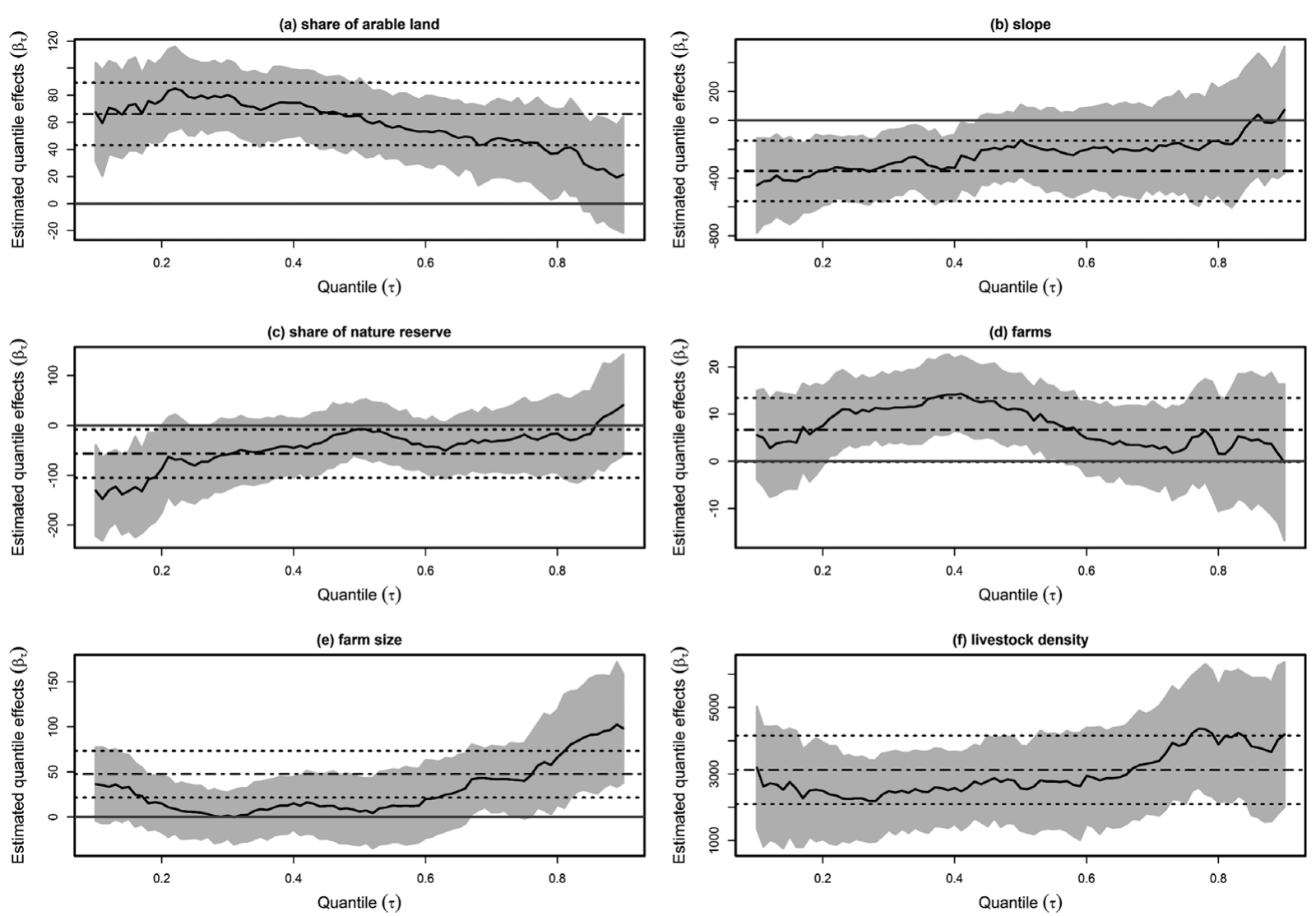

Figure 2. Quantile Plots for Estimated Coefficients of Agricultural Factors Influencing Standard Farmland Values in North Rhine-Westphalia (notes: quantile regression indicated by black solid line, quantile regression confidence interval of $95 \%$ indicated by gray shaded area, ordinary least squares [OLS] regression indicated by black dash-and-dot line, OLS regression confidence interval of $95 \%$ indicated by black dotted line, and zero line indicated by gray solid line; source: own estimation) 

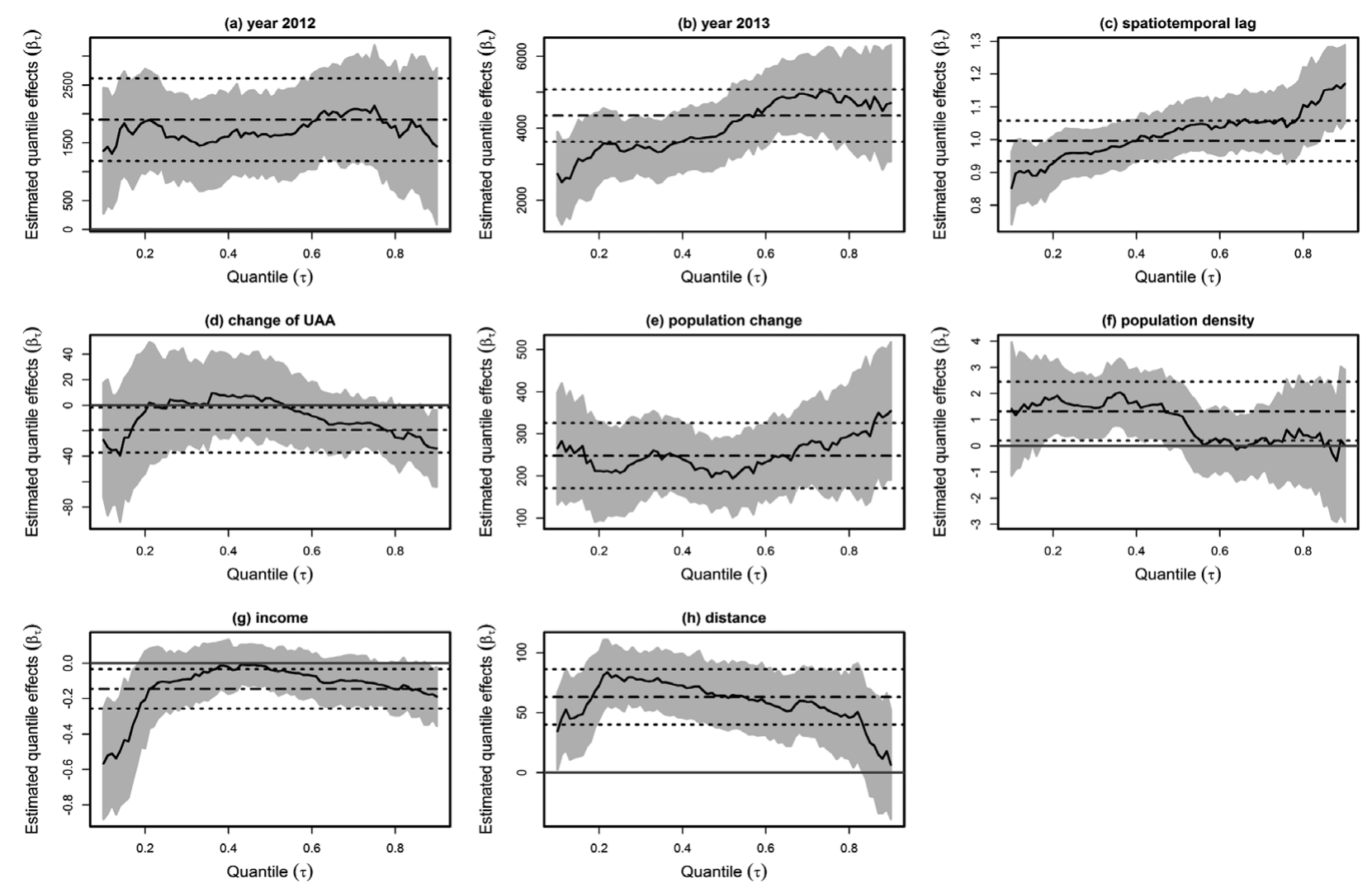

Figure 3. Quantile Plots for Estimated Coefficients of the Time Dummy Variables, the Spatiotemporal Lag, and Nonagricultural Factors Influencing Standard Farmland Values in North Rhine-Westphalia (notes: UAA indicates utilized agricultural area, quantile regression indicated by black solid line, quantile regression confidence interval of $95 \%$ indicated by gray shaded area, ordinary least squares [OLS] regression indicated by black dash-and-dot line, OLS regression confidence interval of $95 \%$ indicated by black dotted line, and zero line indicated by gray solid line; source: own estimation) 
Table 2. Ordinary Least Squares (OLS) and Quantile Regression Estimates of Factors Influencing Standard Farmland Values in North RhineWestphalia

\begin{tabular}{|c|c|c|c|c|c|c|c|}
\hline \multirow[b]{2}{*}{ Variables } & \multirow[b]{2}{*}{ OLS } & \multicolumn{5}{|c|}{ Selected Quantile } & \multirow[b]{2}{*}{ Test Statistic } \\
\hline & & 0.1 & 0.25 & 0.5 & 0.75 & 0.9 & \\
\hline Intercept & $-7,648^{* * *}$ & 1,446 & $-9,276^{* *}$ & $-11,336^{* * *}$ & $-7,445^{*}$ & $-6,022$ & \\
\hline Soil quality & -19.25 & -3.24 & -10.56 & -5.90 & 24.56 & -14.07 & 1.08 \\
\hline Share of arable land & $66.18^{* * *}$ & $67.36^{* * *}$ & $77.90^{* * *}$ & $65.03^{* * *}$ & $44.60^{* *}$ & 21.39 & $2.17^{\circ}$ \\
\hline Share of UAA & -9.83 & 7.42 & -9.23 & 12.05 & -25.86 & -10.20 & 1.16 \\
\hline Slope & $-351.40^{* *}$ & $-451.09^{* *}$ & $-338.72^{* *}$ & -138.67 & -179.41 & 73.36 & $2.37^{\circ}$ \\
\hline Change of UAA & $-19.41^{*}$ & -27.37 & -2.54 & 5.54 & -15.07 & $-33.85^{*}$ & 1.35 \\
\hline AUM & 3.49 & 1.04 & 7.21 & 5.27 & 0.29 & -1.77 & 0.18 \\
\hline NSG & $-56.39^{*}$ & $-130.47^{* *}$ & $-80.59^{*}$ & -6.77 & -17.99 & 41.48 & $5.02^{* * *}$ \\
\hline WSG & -36.83 & 17.54 & -11.99 & -19.44 & -42.34 & -66.74 & 1.21 \\
\hline Farms & $6.66^{\circ}$ & 5.56 & $10.09^{* *}$ & $11.00^{* *}$ & 2.77 & -0.23 & $2.45^{*}$ \\
\hline Farm size & $47.60^{* * *}$ & $36.67^{\circ}$ & 5.71 & 6.26 & $40.26^{\circ}$ & $98.13^{* *}$ & $7.88^{* * *}$ \\
\hline Full-time share & 22.14 & -18.09 & $28.28^{\circ}$ & $28.14^{\circ}$ & 19.68 & 28.95 & $1.95^{\circ}$ \\
\hline Livestock density & $3,127^{* * *}$ & $3,196^{* *}$ & $2,276^{* * *}$ & $2,575^{* * *}$ & $3,919 * * *$ & $4,191^{* * *}$ & $2.43^{*}$ \\
\hline Biogas & -141.80 & $-3,839^{*}$ & 133.37 & -158.98 & 1,740 & 2,752 & $3.52^{* *}$ \\
\hline Wind & $182.80^{* *}$ & 46.67 & 108.30 & 123.83 & 98.96 & $253.83^{\circ}$ & 0.62 \\
\hline Population density & $1.32^{*}$ & 1.41 & $1.55^{*}$ & $1.19^{\circ}$ & 0.16 & 0.01 & 0.85 \\
\hline Population change & $248.20^{* * *}$ & $265.80^{* * *}$ & $207.59^{* * *}$ & $211.77^{* * *}$ & $261.00^{* * *}$ & $354.51^{* * *}$ & $2.26^{\circ}$ \\
\hline House construction & 2.47 & 3.85 & 1.66 & 1.50 & 5.72 & 4.44 & 0.59 \\
\hline Income & $-0.14^{*}$ & $-0.57^{* * *}$ & -0.11 & -0.04 & -0.11 & $-0.19^{* *}$ & $6.28^{* * *}$ \\
\hline Distance & $63.09^{* * *}$ & $34.63^{*}$ & $78.96^{* * *}$ & $64.55^{* * *}$ & $51.76^{* *}$ & 6.44 & $6.73^{* * *}$ \\
\hline Spatiotemporal lag & $0.996^{* * *}$ & $0.85^{* * *}$ & $0.96^{* * *}$ & $1.04^{* * *}$ & $1.07^{* * *}$ & $1.17^{* * *}$ & $8.49^{* * *}$ \\
\hline Dummy 12 & $1,900^{* * *}$ & $1,362^{* *}$ & $1,588^{* * *}$ & $1,606^{* * *}$ & $2,141^{* * *}$ & $1,439^{\circ}$ & 0.99 \\
\hline Dummy 13 & $4,352^{* * *}$ & $2,734^{* * *}$ & $3,378^{* * *}$ & $3,883^{* * *}$ & $5,008^{* * *}$ & $4,698^{* * *}$ & $4.22^{* * *}$ \\
\hline Pseudo $R^{2}$ ( $R^{2}$ for OLS) & 0.876 & 0.642 & 0.695 & 0.677 & 0.646 & 0.639 & \\
\hline Number of observations & 1,416 & & & & & & \\
\hline
\end{tabular}

Notes: Symbols $\left({ }^{\circ},{ }^{*},{ }^{*},{ }^{* *}\right)$ indicate significance at the $10 \%, 5 \%, 1 \%$, and $0.1 \%$ level, respectively. R command "rq" is used for estimation (Koenker, 2017 ) UAA: utilized agricultural area.

Source: Own estimation. 
quantiles. This finding reveals that covariates with varying effects across the conditional distribution of SFVs exist. The plots of the covariates' slope and share of nature reserve show a similar result. An increase of both variables indicates less favorable conditions for agricultural production in terms of higher production costs as a steep land slope can hamper the use of heavy machinery or sometimes exclude the cultivation of certain crops (e.g., maize) (Schmidtner, Dabbert, and Lippert, 2015), and the associated regulations with nature reserves restrict the allowed production intensity (Mährlein, 2017). These relationships are confirmed by the significantly negative coefficients in the OLS regression. An increase of $1 \%$ results in a price discount of $€ 350$ per hectare for the slope of land and of $€ 56$ per hectare for the share of nature reserves. Again, the quantile regression estimates reveal a more differentiated picture. Both factors only negatively affect the SFVs in the lower half of the conditional distribution. A $1 \%$ increase of slope decreases the SFV by $€ 340$ to $€ 450$ per hectare, while the same change of the share of nature reserve results in a price discount by $€ 80$ to $€ 130$ per hectare. Hence, all three land characteristics are only significant or at least more pronounced in the lower half of the conditional distribution, and the lowest quantile (0.1-quantile) reveals stronger effects compared with OLS regression.

The number of farms is not significant at a 5\% level in the OLS regression, whereas the quantile regression shows a significant positive impact in the middle of the conditional distribution. Here, an increase of competition by 10 farms lets the SFVs for arable land increase by $€ 100$ per hectare. The positive impact of the full-time share in this part of the distribution (only significant at the $10 \%$ level) indicates that this competition mainly stems from full-time farms requiring additional land for successful continuation of their agricultural business. The farm size positively influences the SFVs for arable land based on the OLS regression. A growth of 10 hectares per farm results in an increase of $€ 480$ per hectare. In the quantile regression, such an effect can only be detected in the upper tail of the conditional distribution, but there, the impact is twice as high. This result indicates that the lower half of the conditional price distribution might be dominated by local competition for land between diverse farms. However, for prices is the upper tail of the conditional distribution, only larger farms might be able to compete with other farmland buyers because of economy of scales and related higher willingness to pay of these farms.

Livestock density has a strong price-increasing impact on SFVs for arable land regardless of the estimation method. However, once more, the quantile regression gives a more complete picture in that it shows that the positive impact is much stronger in the higher quantiles. An increase of one livestock unit per hectare results in an increase of SFVs by $€ 3,127$ per hectare according to the OLS regression. With an increase by $€ 4,191$ per hectare in the 0.9quantile for a one-unit increase in livestock density, the price-increasing impact is about one-third higher. The positive correlation mainly stems from high returns 
of livestock production and several German legal regulations that encourage livestock farmers to pay high farmland prices for additional land, particularly in regions characterized by a high agglomeration of poultry and swine farms like in NRW.

Figure 3 shows the estimated coefficients of the time dummy variables, the spatiotemporal lag, and nonagricultural factors influencing SFVs. As expected, given the considerable increase of farmland prices during the last decade (Destatis, 2017a), both dummy variables for the years 2012 and 2013 have a significant positive impact. In the OLS regression, SFVs increased by $€ 4,300$ per hectare in 2013, which is twice as high compared with 2012. Looking at the quantile regression provides additional information. Although the price-increasing effect is relatively stable in 2012, the effect increases across the conditional distribution for 2013. Hence, conditionally high farmland prices have additionally undergone higher price increases in 2013. The spatiotemporally lagged variable is positive and significant in both estimation methods. The coefficient is close to 1 in the OLS regression indicating that an increase in the average neighboring SFV by $€ 1$ per hectare raises the SFV in the respective municipality by 99.6 euro cents per hectare. The quantile regression shows a continually increasing effect over the quantiles. In the upper tail of the conditional distribution, the coefficient exceeds 1 , which also reflects stronger price increases of the conditionally higher SFVs during the period considered. At this point, we note that we compared the estimation results with the results of the semilog model specification (transformation of logarithm is used for the SFV and its spatiotemporal lag, but not for the right-hand sight variables; not shown here) to check the robustness of the estimation results. The variation of the spatiotemporal lag effect differs between both models, while the impacts of the other explanatory variables remain relatively unchanged. In the semilog model, the coefficient of the spatiotemporal lag reaches its maximum in the middle of the conditional distribution. Hence, the spatial relationship between the SFV and its neighboring values (as defined in this study) is not clear and has to be interpreted with caution. However, both model specifications show a positive and significant impact of the neighborhood.

The impact of nonfarm factors can be separated into two price-increasing effects of urban sprawl: conversion of farmland to urban uses and speculative effects as represented by farmland conversion risk (Livanis et al., 2006). The impact of change of utilized agricultural area is the first piece of evidence regarding the impact of nonagricultural land use. Loss of utilized agricultural area is mainly caused by land use because of the development of new settlement and transport areas. Although the OLS regression shows a significantly negative impact, resulting in a price-increasing impact of $€ 20$ per hectare if farmland is lost by $1 \%$, the quantile regression shows such an effect only in the highest quantiles. Here, a $1 \%$ loss of farmland causes the SFVs to increase by $€ 30$ per hectare. The exclusive significance in the 0.9 -quantile indicates that nonagricultural land 
use is more pronounced in the upper tail of the conditional distribution of SFVs. Population change as an indicator for the speculative component supports this finding. Although its impact is significantly positive in both estimation methods, the impact becomes stronger in the upper tail of the conditional distribution according to the quantile regression. A population growth of $1 \%$ leads to an increase of SFVs by $€ 248$ per hectare in the OLS regression compared with an increase by $€ 355$ per hectare in the 0.9 -quantile. The price-increasing impact of nonagricultural land use was also found in previous studies analyzing the impact of urban sprawl (Cavailhès and Thomas, 2013; Livanis et al., 2006). In contrast, population density only positively influences the SFVs in the 0.25 and 0.5 quantiles. According to the OLS regression, there is a general price-increasing effect of population density because of a higher demand of or speculation for land conversion to nonagricultural land use. An increase of 100 inhabitants per $\mathrm{km}^{2}$ leads to an increase of $€ 130$ per hectare arable land. The impacts of the quantile regression are similar. The reason why population density does not affect the SFVs in the upper tail of the conditional distribution might be that this demand is more concentrated in suburban regions rather than in the most populous cities directly. That is, people prefer to live close to big cities, but not directly in them because suburban regions provide some natural amenities. The distance to big cities is significantly positive in the OLS regression. This appears to be somewhat conflicting to our previous results, which suggest that SFVs significantly decrease as one moves farther from the urban center. However, the quantile regression shows that the impact becomes insignificant at the higher quantiles. With regard to the results of the other explanatory variables, the effect of distance might be better explainable. On the one hand, agricultural factors indicating good agricultural productivity (share of arable land, slope) seem to be more pronounced in the lower tail of the conditional distribution where the positive impact of distance might indicate that these regions are farther away from big cities. On the other hand, nonagricultural factors seem to be more pronounced in the upper tail of the conditional distribution. Because nonagricultural land use becomes more likely as one moves further toward the city, the positive impact of distance because of agricultural purposes becomes insignificant in the highest quantiles.

Income negatively affects SFVs in the OLS regression. Here, an increase of $€ 1,000$ per inhabitant results in a price discount of $€ 140$ per hectare arable land. In the quantile regression, such an effect can only be found in both tails of the conditional distribution. The significance level and the coefficient are higher in the 0.1 -quantile. Here, an increase of $€ 1,000$ per inhabitant decreases the SFV by $€ 570$ per hectare. This negative effect might indicate that good nonagricultural earning opportunities lead to a higher share of part-time farmers who do not want to buy farmland. As the lower half of the conditional distribution is dominated by the effects of agricultural competition for land (indicated by the more pronounced land and farm characteristics), it is reasonable that the effect of 
income is stronger in the 0.1 -quantile. Finally, we found a price-increasing impact of wind power in the OLS regression and in the 0.9-quantile. Higher returns from wind power plants can explain the price premium (Ritter et al., 2015). However, this should also apply to biogas plants. Additionally, biogas plants should lead to higher competition for land from the cultivation of energy crops (Hennig and Latacz-Lohmann, 2017). Hence, the significant negative correlation in the 0.1quantile is difficult to explain. Although we included a comprehensive set of potential influencing factors, a plausible explanation to the unexpected result could be because of the omitted variable problem. It is possible that the biogas variable rather reflects an unobserved locational or structural factor in the lower tail of the conditional distribution leading to the unexpected sign.

The last column of Table 2 shows the test statistic for the equality of slopes (i.e., tests if at least one coefficient is significantly different from other coefficients estimated at other quantiles), which is a variant of the Wald test described in Koenker and Bassett (1982). Consequently, the significant test statistic for some of the explanatory variables underlines the suitability of the quantile regression approach. We also tested whether the model in the upper quantiles, represented here by the 90 th quantile, is the same as the median model (50th quantile) and as the lower quantiles (represented by the 10th quantile). Both Wald-type joint tests for equality of slopes are highly significant, demonstrating the difference of the quantile regression model in the upper quantiles and the rest of the sample.

\section{Discussion and Conclusion}

Our results reveal several influencing factors with heterogeneous effects across the quantiles of SFVs, and thus our findings are consistent with the results of previous studies (Kostov, 2009b; März et al., 2016; Mishra and Moss, 2013; Peeters, Schreurs, and van Passel, 2017; Uematsu, Khanal, and Mishra, 2013). Overall, land and farm characteristics as well as nonagricultural factors are important price determinants for SFVs. Although this conclusion could also be drawn from the OLS regression results, quantile regression provides more information about the relationships. The effects considerably vary across the conditional distribution. Land and farm characteristics are important price determinants in the lower tail of the conditional distribution. Furthermore, we find some evidence that the price-increasing impacts of livestock production and nonagricultural factors, such as relative population change and loss of utilized agricultural area, are more pronounced in the upper tail of the conditional distribution leading to an underestimation of these effects by OLS regression in this part of the distribution. Concluding, these factors are the main price drivers for SFVs, especially in the highest quantiles. This information would have been left unnoticed by using a conventional least squares regression. Following Uematsu, Khanal, and Mishra (2013), we argue that factors indicating livestock production and nonagricultural land use opportunities might be luxury 
attributes of farmland and thus are more pronounced in the upper tail of the conditional distribution of SFVs, whereas factors related to land productivity and local competition for land might be necessary attributes of farmland and thus are more pronounced in the lower tail of the conditional distribution of SFVs.

According to the results, the impact of the proposed price caps for farmland needs to be discussed differentiated. Price caps should not affect farmland transactions in the lower quantiles (i.e., conditionally lower-priced parcels). Here, prices are stronger determined by productivity and farm characteristics (share of arable land, slope, number of farms, etc.), and thus the willingness to pay is mainly oriented on the agricultural value of farmland. This type of farmland should be still affordable for farmers. In contrast, farmland prices in the upper quantiles (i.e., conditionally higher-priced parcels) are more strongly determined by nonagricultural characteristics (besides livestock production). This means the demand of farmland for nonagricultural land use mainly acts as a price driver in the upper quantiles in our study area. Except for the city states, NRW is the federal state with the highest population density, and thus a high share of farmland is influenced by urban sprawl. As a consequence, access to farmland might be challenging for farmers and might give some evidence that the recent farmland price level could regionally be already higher than the earning capacity per hectare for many farmers. This might be a comprehensible reason for stronger interventions in the farmland market. At first glance, proposed price caps could be a suitable measure of intervention as it is more likely that farmland transactions in the upper quantiles will exceed a price cap, and thus these transactions would be prevented.

However, the impacts on the different groups of sellers and buyers also have to be considered. The proposed policy of capping farmland prices would negatively affect current farmland owners, who would like to sell their land at a high price. The ownership structure of farmland is quite diverse in Germany. Although statistical data are missing, sellers of farmland are predominantly nonagricultural heirs of former farmers. This group would be most severely affected. This disadvantage may be justified by the public interest of ensuring affordable agricultural land for farmers. Buyers of farmland would mainly benefit because high-priced farmland would become less expensive. This would also be true for the government itself when farmland is needed for infrastructure measures. However, generalized price caps would also lead to a considerable disadvantage for prospective buyers. For example, livestock and horticulture farmers, outstandingly successful farmers, and growing farms usually have a higher willingness to pay for additional land (partly based on marginal value perspectives). For livestock farmers, this relationship is clearly demonstrated in the empirical results. By introducing a price cap, these groups of buyers might not be able any longer to win against the competitors by high bids. Thus, their access to additional farmland could be limited. In the worst case, all prospective 
buyers offer the same price equal to the price cap. The willingness to pay would no longer be a deciding feature of who gets the parcel of land. Consequently, the best farmer may not win the bid leading to inferior market results.

Thus, intervention might be more effective and efficient by directly regulating the price drivers in the upper tail of the conditional distribution to limit further price increases instead of the currently discussed generalized price caps (like an arbitrary price bid threshold as a percentage of an average price level). This would also lead to regionally adjusted measurements as the main price drivers may also differ according to respective regional conditions. For example, reducing urban sprawl and paring down the loss of agricultural land to a minimum should be an effective and efficient measurement to limit further price increases in our study area, NRW.

One major limitation of our study is the aggregation level of data. The SFV for arable land at the municipal level in NRW is aggregated twice. First, the SFV is an average value of single farmland sale prices obtained from the data on purchasing prices of the real estate appraiser board in NRW. Thus, it is an aggregated value in itself. Second, we had to aggregate the SFVs at the municipal level for analyzing because of the lack of information about the location of the different SFV zones in a municipality as well as the lack of availability of explanatory variables at a less aggregated level. This could be the reason for the unexpected sign of biogas production in our empirical results. Moreover, it is reasonable to expect that the heterogeneity of covariate effects found here would become more obvious if single sale prices of farmland are used. Hence, we recommend improving the availability and quality of data for further analyses of factors influencing farmland values.

Despite the aggregation level of data, this study still clearly shows that the impacts of farmland price determinants can vary across the conditional distribution. Thus, quantile regression seems to be very suitable to detect the main price drivers and the consequential best interventions, and therefore, it proves to be a good addition to conventional least squares methods for developing policy recommendations.

\section{References}

Anselin, L. Spatial Econometrics: Methods and Models. Dordrecht, the Netherlands: Kluwer Academic, 1988.

Barrodale, I., and F. Roberts. "Algorithm 552. Solution of the Constrained 11 Linear Approximation Problem [F4]." ACM Transactions on Mathematical Software 6,2(1980):231-35.

Borchers, A., J. Ifft, and T. Kuethe. "Linking the Price of Agricultural Land to Use Values and Amenities.” American Journal of Agricultural Economics 96,5(2014):1307-20.

Breustedt, G., and H. Habermann. "The Incidence of EU Per-Hectare Payments on Farmland Rental Rates." Journal of Agricultural Economics 62,1(2011):225-43. 
Cavailhès, J., and I. Thomas. "Are Agricultural and Developable Land Prices Governed by the Same Spatial Rules? The Case of Belgium." Canadian Journal of Agricultural Economics 61,3(2013):439-63.

Dillard, J.G., T.H. Kuethe, C. Dobbins, M. Boehlje, and R.J. Florax. "The Impacts of the Tax-Deferred Exchange Provision on Farm Real Estate Values." Land Economics 89,3(2013):479-89.

European Commission. "Commission Interpretative Communication on the Acquisition of Farmland and European Union Law." Official Journal of the European Union 60,C 350(2017):5-20.

European Union. “Eurostat - Landpreise und Pachten - jährliche Daten.” Internet site: https: //data.europa.eu/euodp/en/data/dataset/uzgHCL99F3w86KZcbQCA (Accessed April 3, 2018).

Federal Government Working Group (BLAG). Landwirtschaftliche Bodenmarktpolitik: Allgemeine Situation und Handlungsoptionen. Bericht der Bund-Länder-Arbeitsgruppe „Bodenmarktpolitik“. 2015. Internet site: http://www.bmel.de/SharedDocs/ Downloads/Landwirtschaft/LaendlicheRaeume/Bodenmarkt-Abschlussbericht-BundLaender-Arbeitsgruppe.pdf?_blob=publicationFile (Accessed August 7, 2015).

Federal Institute for Geosciences and Natural Resources (BGR). Nutzungsdifferenzierte Bodenübersichtskarte der Bundesrepublik Deutschland 1:1.000.000 (BÜK 1000 N2.3). Hannover, Germany: BGR, 2015.

Federal Office for Agriculture and Food (BLE). Zahlungen aus den Europäischen Fonds für Landwirtschaft und Fischerei. Bonn-Mehlem, Germany: BLE, 2015.

Federal Statistical Office (Destatis). Land- und Forstwirtschaft, Fischerei. Kaufwerte für landwirtschaftliche Grundstücke, 2016. Fachserie 3, Reihe 2.4. Wiesbaden, Germany: Destatis, 2017a.

- "The Regional Database Germany." Internet site: https://www.regionalstatistik.de/ genesis/online/logon (Accessed November 20, 2017b).

Feichtinger, P., and K. Salhofer. "The Fischler Reform of the Common Agricultural Policy and Agricultural Land Prices." Land Economics 92, 3(2016):411-32.

Firpo, S., N.M. Fortin, and T. Lemieux. "Unconditional Quantile Regressions.” Econometrica 77,3(2009):953-73.

GeoBasis-DE/Federal Agency for Cartography and Geodesy (BKG). Digitales Geländemodell. Gitterweite 200 m. DGM 200. Frankfurt am Main, Germany: BKG, 2015a.

- Verwaltungsgebiete der Bundesrepublik Deutschland. Anwendungsmaßstab 1: 250.000. Stand 01.01.2011. Frankfurt am Main, Germany: BKG, 2015b.

Heckman, J.J. "Sample Selection Bias as a Specification Error." Econometrica 47,1(1979): 153-61.

Hennig, S., and U. Latacz-Lohmann. "The Incidence of Biogas Feed-in Tariffs on Farmland Rental Rates - Evidence from Northern Germany." European Review of Agricultural Economics 44,2(2017):231-54.

Huang, H., G.Y. Miller, B.J. Sherrick, and M.I. Gómez. "Factors Influencing Illinois Farmland Values." American Journal of Agricultural Economics 88,2(2006): 458-70.

Hüttel, S., M. Odening, K. Kataria, and A. Balmann. "Price Formation on Land Market Auctions in East Germany - An Empirical Analysis." German Journal of Agricultural Economics 62,2(2013):99-115.

Hüttel, S., and L. Wildermann. "Price Formation in Agricultural Land Markets - How Do Different Acquiring Parties and Sellers Matter?" Neuere Theorien und Methoden in den 
Wirtschafts- und Sozialwissenschaften des Landbaus. Vol. 50. Schriften der Gesellschaft für Wirtschafts- und Sozialwissenschaften des Landbaus (e.V.), ed. Münster, Germany: Landwirtschaftsverlag, 2015, pp. 125-42.

Kim, H., S.W. Park, S. Lee, and X. Xue. "Determinants of House Prices in Seoul: A Quantile Regression Approach.” Pacific Rim Property Research Journal 21,2(2015): 91-113.

Koenker, R. Quantile Regression. Cambridge: Cambridge University Press, 2005.

—. Quantile Regression in R: A Vignette. Internet site: https://cran.r-project.org/web/ packages/quantreg/vignettes/rq.pdf (Accessed August 7, 2017).

Koenker, R., and G. Bassett. "Regression Quantiles.” Econometrica 46,1(1978):33-50.

—. "Tests of Linear Hypotheses and 1"1 Estimation.” Econometrica 50,6(1982):1577-84.

Koenker, R., and K.F. Hallock. "Quantile Regression.” Journal of Economic Perspectives 15,4(2001):143-56.

Koenker, R., and V. d'Orey. “Algorithm AS 229: Computing Regression Quantiles.” Journal of the Royal Statistical Society: Series C (Applied Statistics) 36,3(1987):383-93.

—. "Remark AS R92: A Remark on Algorithm AS 229: Computing Dual Regression Quantiles and Regression Rank Scores." Journal of the Royal Statistical Society: Series C (Applied Statistics) 43,2(1994):410-14.

Kostov, P. "Spatial Dependence in Agricultural Land Prices: Does It Exist?" Agricultural Economics 40, 3(2009a):347-53.

_. "A Spatial Quantile Regression Hedonic Model of Agricultural Land Prices." Spatial Economic Analysis 4,1(2009b):53-72.

Kuethe, T.H., and R. Keeney. "Environmental Externalities and Residential Property Values: Externalized Costs along the House Price Distribution." Land Economics 88,2(2012):241-50.

Landesdatenbank NRW. Internet site: https://www.landesdatenbank.nrw.de/ldbnrw/online (Accessed June 10, 2017).

Landwirtschaftszählung. Livestock Population at Municipal-Level of the Agricultural Census. North Rhine-Westphalia, Germany: Federal Statistical Office of North RhineWestphalia, 2010.

LeSage, J. Spatial Econometrics. 1998. Internet site: http://www.spatial-econometrics.com/ html/wbook.pdf (Accessed April 3, 2018).

LeSage, J., and R.K. Pace. Introduction to Spatial Econometrics. Boca Raton, FL: Taylor and Francis, 2009.

Liao, W.-C., and X. Wang. "Hedonic House Prices and Spatial Quantile Regression.” Journal of Housing Economics 21,1(2012):16-27.

Livanis, G., C.B. Moss, V.E. Breneman, and R.F. Nehring. "Urban Sprawl and Farmland Prices." American Journal of Agricultural Economics 88,4(2006):915-29.

Maddison, D. "A Spatio-Temporal Model of Farmland Values." Journal of Agricultural Economics 60,1(2009):171-89.

Mährlein, A. "Inanspruchnahme landwirtschaftlicher Flächen durch Naturschutzmaßnahmen." Agrarbetrieb 5(2017):370-80.

März, A., N. Klein, T. Kneib, and O. Musshoff. "Analysing Farmland Rental Rates using Bayesian Geoadditive Quantile Regression.” European Review of Agricultural Economics 43,4(2016):663-98.

McMillen, D. "Conditionally Parametric Quantile Regression for Spatial Data: An Analysis of Land Values in Early Nineteenth Century Chicago." Regional Science and Urban Economics 55(November 2015):28-38. 
McMillen, D.P. "Perspectives on Spatial Econometrics: Linear Smoothing with Structured Models." Journal of Regional Science 52,2(2012):192-209.

Mishra, A.K., and C.B. Moss. "Modeling the Effect of Off-Farm Income on Farmland Values: A Quantile Regression Approach.” Economic Modelling 32(May 2013):361-68.

Nilsson, P., and S. Johansson. "Location Determinants of Agricultural Land Prices." Review of Regional Research 33,1(2013):1-21.

Palmquist, R.B. "Hedonic Methods." Measuring the Demand for Environmental Quality. J.B. Braden and C.D. Kolstad, eds. Amsterdam: North-Holland, 1991, pp. 77-120.

Patton, M., and S. McErlean. "Spatial Effects within the Agricultural Land Market in Northern Ireland." Journal of Agricultural Economics 54,1(2003):35-54.

Peeters, L., E. Schreurs, and S. van Passel. "Heterogeneous Impact of Soil Contamination on Farmland Prices in the Belgian Campine Region: Evidence from Unconditional Quantile Regressions.” Environmental and Resource Economics 66,1(2017):135-68.

Ready, R.C., and C.W. Abdalla. "The Amenity and Disamenity Impacts of Agriculture: Estimates from a Hedonic Pricing Model." American Journal of Agricultural Economics 87,2(2005):314-26.

Ritter, M., S. Hüttel, M. Walter, and M. Odening. "Der Einfluss von Windkraftanlagen auf landwirtschaftliche Bodenpreise.” Berichte über Landwirtschaft 93,3(2015):1-15.

Rosen, S. "Hedonic Prices and Implicit Markets: Product Differentiation in Pure Competition." Journal of Political Economy 82,1(1974):34-55.

Schmidtner, E., S. Dabbert, and C. Lippert. "Do Different Measurements of Soil Quality Influence the Results of a Ricardian Analysis? A Case Study on the Effects of Climate Change on German Agriculture." German Journal of Agricultural Economics 64,2(2015):89-106.

State Office for Nature, Environment and Consumer Protection North Rhine-Westphalia (LANUV). Internet site: http://www.naturschutzinformationen-nrw.de/nsg/de/ downloads (Accessed June 11, 2015).

Uematsu, H., A.R. Khanal, and A.K. Mishra. "The Impact of Natural Amenity on Farmland Values: A Quantile Regression Approach.” Land Use Policy 33(July 2013):151-60.

U.S. Department of Agriculture, National Agricultural Statistics Service. Land Values 2016 Summary. 2016. Internet site: http://usda.mannlib.cornell.edu/usda/nass/AgriLandVa/ 2010s/2016/AgriLandVa-08-05-2016.pdf (Accessed April 3, 2018).

Yoo, J., and T. Frederick. "The Varying Impact of Land Subsidence and Earth Fissures on Residential Property Values in Maricopa County - A Quantile Regression Approach.” International Journal of Urban Sciences 12,2(2017):1-13.

Zhang, L. "Flood Hazards Impact on Neighborhood House Prices: A Spatial Quantile Regression Analysis." Regional Science and Urban Economics 60(September 2016):1219.

Zietz, J., E.N. Zietz, and G.S. Sirmans. "Determinants of House Prices: A Quantile Regression Approach.” Journal of Real Estate Finance and Economics 37,4(2008):317-33. 